Dendrites are more spiny on mature hippocampal neurons when synapses are inactivated Sergei A. Kirov and Kristen M. Harris

Nat. Neurosci. 2, 878-884 (1999)

Because of an editorial error, a sentence in the Methods was misprinted. The penultimate sentence of the third paragraph in the methods section should read as follows:

"MCPG was solubilized at 100X final concentration in 1.1 eq. of $\mathrm{NaOH} . "$

\title{
Loss of attentional stimulus selection after extrastriate cortical lesions in macaques
}

Peter De Weerd, Modesto R. Peralta III, Robert Desimone and Leslie G. Ungerleider

Nat. Neurosci. 2, 753-758 (1999)

Due to an printing error, Fig. 3a was printed with a dotted appearance. The corrected version appears below.

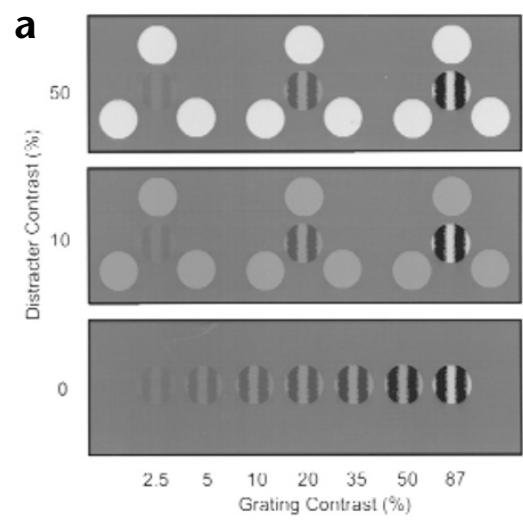

Microsaccadic eye movements and firing of single cells in the striate cortex of macaque monkeys Susana Martinez-Conde, Stephen L. Macknik and David H. Hubel

Nat. Neurosci. 3, 251-258 (2000)

Because of an editorial error, the last four references were omitted from the reference list. The last four references are:

24. Albrecht, D. G. \& Hamilton, D. B. Striate cortex of monkey and cat: contrast response function. J. Neurophysiol. 48, 217-237 (1982).

25. Albrecht, D. G. Visual cortex neurons in monkey and cat: effect of contrast on the spatial and temporal phase transfer functions. Vis. Neurosci. 12, 1191-1210 (1995).

26. Gawne, T. J., Kjaer, T. W. \& Richmond, B. J. Latency: another potential code for feature binding in striate cortex. J. Neurophysiol. 76, 1356-1360 (1996).

27. Judge, S. J., Richmond, B. J. \& Chu, F. C. Implantation of magnetic search coils for measurement of eye position: an improved method. Vision Res. 20, 535-538 (1980).

corrections

\section{Receptive fields of disparity-selective neurons in macaque striate cortex}

Margaret S. Livingstone and Doris Y. Tsao

Nat. Neurosci. 2, 825-832 (1999)

The scales in Figs. 2, 3 and 5 were mislabeled. The '\% difference' scales on Figs. 2, 3 and 5 should show maximum values of $50 \%$ and not $100 \%$. The authors regret the error.

\section{Stockpiling PhDs for the new millenium}

Nat. Neurosci. 2, 1039 (1999)

Some of the data from the ANDP survey were quoted incorrectly. The last line of the first paragraph should read as follows:

"The ANDP survey (which will be published early next year) found a threefold increase in the annual number of PhD degrees awarded specifically in neuroscience over the last ten years; moreover, the total number of students in neuroscience PhD programs has almost doubled between 1986 and 1998."

The editors regret the error. 